\title{
Investigating the prevalence of congenital anomalies and its associated factors in Ilam city
}

\author{
Kourosh Sayehmiri ${ }^{1}$, Mohammad Reza Kaffashian ${ }^{2}$, Elahe Ranaei ${ }^{3 *}$
}

1. Research Center for Prevention of Psychosocial trauma, Ilam University of Medical Sciences, Ilam, Iran

2. Department of Physiology, Faculty of Medicine, Ilam University of Medical Sciences, Ilam, Iran

3. Department of Anatomy, Faculty of Medicine, Ilam University of Medical Sciences, Ilam, Iran

*Corresponding author: Tel: +98 9183418801 Fax: +98 8432232521

Address: Department of Anatomy, Faculty of Medicine, Ilam University of Medical Sciences, Ilam, Iran E-mail: delnianoori@gmail.com

Received; 2015/04/8 revised; 2015/05/10 accepted; 2015/06/28

\begin{abstract}
Introduction: Congenital anomalies are a common cause of disability and mortality in newborns and their treatments involves high costs for the society. This study aimed to investigate the prevalence of congenital anomalies and their causes.

Materials and methods: This research was a descriptive-analytical study and the population included all the newborns in hospitals of the city of Ilam in 2011. Variables of abnormality type, birth status, and medical and genetic illness histories were included into the data collection forms. Data was analyzed through Chi-square tests and Fisher's exact test using SPSS software.

Results: Of 460 neonates, 5.4 percent ( 25 cases) had died at birth and 3.7 percent (16 infants) were born with a birth defect. 43.8 percent of malformed babies had a family history. $31.3 \%$ of the malformed babies had genetic syndromes, whose parents had consanguineous marriage. $18.8 \%$ of babies with defects in the central nervous system and cardiovascular system showed a similar percentage of disorder. The defect in the urinary system, head and neck each accounted for 12.5 percent.
\end{abstract}

Conclusion: This study shows that consanguineous marriages can be the most common genetic cause of genetic syndromes.

Keywords: Congenital malformations, Genetic syndromes, Consanguineous Marriages

\section{Introduction}

Genetic factors play an important role in the deaths of infants and children. Awareness of the impact of genetic diseases and following preventive measures for expectant mothers and their families requires a good strategy and health care (1). Necessary information about the history of genetic disease in the family and care strategies for infants helps to prevent complications and mortality genetic diseases and congenital anomalies and thus assist in the development of health care. Consanguineous marriage is known as a risk for increasing the likelihood of birth defect. Quantifying this risk is difficult in populations that consanguinity is common (2).

Abnormalities and genetic disorders currently make up a significant proportion of complications of children. $22 \%$ of infant mortality is due to congenital anomalies and genetic disorders (3). $5 \%$ of all infants have congenital defects at birth and $2 \%$ have major malformations (4). Interactions of environment and genetic factors, as well as, other unknown causes have the greatest 
impact on the incidence of abnormalities (5).

The incidence of congenital malformations is different among various ethnic groups (6). Consanguinity among some ethnic groups has an important role in the occurrence of abnormalities (7). In most Muslim countries such as Morocco and Pakistan where $20-80 \%$ of marriages occur among between relatives which, the prevalence of abnormalities is more among Muslims than other religions. This issue is attributed to religious believes regarding avoiding abortion among Muslims and consanguineous marriage. Offspring of consanguineous marriages are more at risk of genetic syndromes (8 and 9). Since the treatment of congenital anomalies involves high costs for the society, prevention of congenital malformations is more economical for society (10). The daily intake of 400 micrograms of folic acid by mothers during pregnancy can reduce neural tube closure defects (NTD) (11). This study aims to investigate the prevalence of congenital anomalies in the city of Ilam and their causes.

\section{Materials and methods}

This is a descriptive-analytical study conducted on hospital newborns in Ilam from April to March 2011. To implement the study, visual abnormalities and related factors were identified by reviewing existing records. A self-made questionnaire was used to collect data. Simple sampling was used and all newborns in this interval were included in the study. Babies who were born dead and those who died shortly after birth, as well as those who had incomplete records were excluded from the study. Factors such as mother's age, occupation, maternal disease, history of drug use during pregnancy, dealing with radiation, taking folic acid, consanguineous marriage, genetic disease history, and important points in examining infants were investigated.

\section{Statistical analysis}

Statistical analysis was used to estimate the prevalence of congenital defects. Chisquare tests and Fisher's exact test were used to compare the rate of malformations among boys and girls by using the SPSS 20 software.

\section{Results}

A total of 460 infants were examined among which 25 died at birth and were excluded from the study and 16 infants $(7.3 \%)$ also had at least one visible abnormality. The gender distribution of abnormalities was 7 females (43.8) and 9 males (56.3), but there was no significant relationship between the prevalence of abnormalities and gender $(\mathrm{P}>0.1)$. None of the mothers had a history of a particular disease associated with abnormalities. The radiation exposure and drug consumption were not reported in any of the mothers. 93.8 percent of mothers took folic acid during pregnancy. 43.8 percent had a family history and 56.2 percent were not relative. $31.3 \%$ of malformed babies with genetic syndromes, the parents were consanguineous marriage. $31.3 \%$ of malformed babies with genetic syndromes were from parents who had consanguineous marriage. $18.8 \%$ of infants were deficient in the cardiovascular system and $18.8 \%$ had serious defect in the central nervous system. $12.5 \%$ of infants were deficient in the head and neck, $12.5 \%$ of infants were deficient in the digestive system while $12.5 \%$ of infants had a urinary system defect. 
Table 1. Distribution of abnormalities type in infants born in Ilam in 2011.

\begin{tabular}{lcc}
\hline Abnormal system & Number of abnormality type & Percent of all abnormalities \\
\hline Urinary system defect & 2 & 12.5 \\
Digestive system defect & 2 & 12.5 \\
Genetic syndrome & 5 & 31.3 \\
Cardiovascular system defect & 3 & 18.8 \\
Central nervous system defect & 2 & 12.5 \\
Defects in the head and neck & 2 & 12.5 \\
Total & 16 & 100 \\
\hline
\end{tabular}

Table 2. Demographic characteristics of infants with congenital abnormalities ( $n=16$ infants).

\begin{tabular}{lcc}
\hline Variable & & Percentage of malformed babies \\
\hline Mother's age & Below 18 & 14.6 \\
& $18-35$ & 50.9 \\
& Over 35 & 33.5 \\
\hline Folic acid intake & Yes & 93.8 \\
& No & 6.3 \\
\hline Mother's level of education & Elementary & 43.8 \\
& Diploma & 31.3 \\
& Academic & 18.8 \\
\hline Consanguineous marriage & Yes & 43.8 \\
& No & 56.2 \\
\hline
\end{tabular}

\section{Discussion}

This study aimed at investigating the prevalence of congenital anomalies and their causes. The prevalence of anomalies of Ilam newborns was 3.7 in 2011. The total percentage of abnormal newborns has been reported from $1.8 \%$ to $6.5 \%$ in studies conducted so far (12). The results of similar studies in other parts of the country $(4.7 \%$ in Tehran, $6.5 \%$ in Fasa, $6.2 \%$ in Zanjan) indicate that anomalies are more prevalent in Iran in comparison to other countries. The result of the study in America (13) shows the prevalence of anomalies to be from $0.5 \%$ to $0.8 \%$ and 2.4percent in Australia.

In this study, the prevalence of malformations among boys (56.3\%) was higher than girls but there was no significant relationship between the prevalence of abnormalities and infants' gender. This result is in line with a study conducted in Zanjan'sValiasr hospital in which $71 \%$ ofabnormal babies were male and a study in Shariatii Hospital of Tehran in which $56.8 \%$ of abnormal babies were male $(14,15)$. There were no reports of mother radiation exposure during pregnancy and teratogenic drugs intake among mothers and a history of a disease in this study unlike other reports in research studies that have been done in this area (14-17).

Other research studies have constantly reported significant scientific relations between consanguineous marriage and genetic syndrome (18-19-20). This study also found a significant relationship between consanguineous marriage and genetic syndrome. $31.3 \%$ of all abnormalities were reported to be associated with genetic syndrome as a result of consanguineous marriage. Congenital anomalies can be detected and prevented in utero. Folic acid intake from 3 months before pregnancy can prevent the incidence of anomalies in newborns up to $80 \%$. In addition to this drug therapy, having or not having a lot of diseases in the first 3 months of pregnancy is detectable by the removal of amniotic fluid. It should be noted that abortion is permissible to 3 months in special religious and legal conditions. Taking measures to reduce the incidence of fetal 
malformations is essential by proper planning. Therefore, screening for early detection of fetal abnormalities is recommended. In addition, health personnel who are in contact with women of childbearing age should be advised not to use chemical and herbal medications without a prescription and do not expose themselves to environmental toxins such as cigarette smoke, alcohol and drugs. Groups that are more likely to fetal abnormalities or have a family history of an abnormal child must have a planned pregnancy and use folic acid before pregnancy to the end of the fourth month of pregnancy.

Women should get pregnant under the supervision of a specialist. Also, health authorities should provide necessary measures to control the conditions for mothers who have a history of anomalous child. If some diseases are early diagnosed at birth and there is a suitable diet, the occurrence of some abnormalities can be prevented.

\section{References}

1. Zlotogora J, Haklai Z, Rotem N, Georgi M, Berlovit Z, Levental A, et al. Relative prevalence of malformations at birth among different religious communities in Israel. Am J Med Gent. 2003; 122(1): 59-62.

2. Anastasiadis $P$, Tsikouras $P$, Dafopoulos K, Liberis V, Galazios G, Koutlaki N. Epidemiology of congenital anomalies in differentethcnicities. Clan Exp Obstet Gynecol. 2005; 32(1): 71-4.

3. Perini J, Dames K, Johnston RB. An overview of infant mortality and birth defects in the United States. Teratology.1997; 56: 8-10.

4. Graham J. M. Fetal dysmorphology. Clin Perinatol.1990; 17(3): 513-47.

5. Bruce A. Teratogenic potential of cocaine.Seminar in Perinatology. 1996; 20(2): 93-98, 115.
In developed countries, large investments and serious measures are taken for purification and renewal in the next generation so that people consult with geneticists before marriage and pregnancy. All those who have a history of genetic disorders and anomalies in themselves or their ancestors before you should have genetic counseling before deciding to get married, having a baby, during pregnancy or after childbirth.

\section{Conclusion}

This study shows that about $31.3 \%$ of genetic abnormalities are related to consanguineous marriage in Ilam. Although abnormalities were low in this study, there will probably be a higher prevalence of Ilam city by genetic analysis, finding the cause of spontaneous abortion, infants who were born dead and those who have died immediately after birth.

6. Anthony S, Vander Pal-de bruin KM, Graafmans WC. The reliability of perinatal and neonatal mortality rates: differential under- reporting in linked professional registers VS. Dutch Civil registers. Pediatr Perinatal Epidemiol.2001; 15: 306-14.

7. Terry PB, Bissenden JG, Gondie RG, Mathew PM. Ethnic differences in congenital malformations.Arch Dis Childhood. 1985; 60: 866-8.

8. Shajari h, Mohammadin .Apparent Prevalence of congenital anomalies in infants born at Shariati Hospital in Tehran.Journal Pediatrics in Iran. Volume 16 Issue 3-1385

9. Marzban a. Sadiqzadeh m. Prevalence of disorders of the nervous system marked the born- valiAsr Hospital in Zanjan. Quarterly Mazandaran University of Medical Sciences -1384 
10. Park CH, Stewart W, Khoury MJ, Mulinare J. Is there etiologic heterogeneity between upper \& lower neural tube defects (NTD)? Epidemiology.1992; 136: 1493-1501.

11. Leck I ,Lancashire RJ. Birth prevalence of malformation in members of different ethnic groups and in the offspring of mattings between thems , in Birmingham,England,J Epidemiol Community Health.

12. Youman S. Neurological Surgery. 3rd ed. New York; NY; 1990; (2): p. 39; 40.

13. Lary JM, Paoulozzi LJ. Sex differences in the prevalent of human birth defects: population based study .Teratology .2001: 64:237-51.

14. GaryVF,Harkins ME, Erickson LL, Long-Simpson LK, Holland SE, Burrough Bl. Birth defects ,season of conception, and sex of children born to pesticide applicators living in the Red River vally of
Minnesota,USA. Environ Health Perspect .2002;82:349-52.

15. ChoudhuryAR, Mukher jee M,SharmaA. Study of 1266 consecutive birthes for major congenital defects Indian J Pediatr. 1989 ; 56(4):493-9

16. Sawardekar KP. Profile of major congenital malformations at Nizwahospital ,Oman: 10-year review.JPaediatr Child Health. 2005; 41(7): 323-30.

17. Demirel S, kaplanoglu N, Acar A, Bodur S. Paydak F. The frequency of consanguinity in konya, Turkey, andits medical effects. Genetic Counsel.1997; 8(4): 295-301.

18. Jabber L, Halpern GJ, Shohat M. The impact of consanguinity worldwide. Community Genetics.1998; 1(1): 12-7.

19. Stoll C, Alembik Y, Roth MP, Dott B. Parental consanguinity as a cause for increased incidence of births defects in a study of 239, 942 consecutive births. Consanguinity Birth Defects.1999; 42(3): 133-9. 